\title{
BMJ Open Quality Making every drop count: reducing wastage of a novel blood component for transfusion of trauma patients
}

To cite: McCullagh J, Proudlove N, Tucker $\mathrm{H}$ et al. Making every drop count: reducing wastage of a novel blood component for transfusion of trauma patients. BMJ Open Quality 2021;10:e001396. doi:10.1136/ bmjoq-2021-001396

Received 8 February 2021 Accepted 19 June 2021

\section{Check for updates}

(c) Author(s) (or their employer(s)) 2021. Re-use permitted under CC BY-NC. No commercial re-use. See rights and permissions. Published by BMJ.

${ }^{1}$ NHS Higher Specialist Scientist Training (HSST), DClinSci Programme, The University of Manchester, Manchester, UK

${ }^{2}$ Pathology, Barts Health NHS

Trust, London, UK

${ }^{3}$ Alliance Manchester Business School, The University of Manchester, Manchester, UK

${ }^{4}$ Blizard Institute, Queen Mary, University of London, UK, London, UK

${ }^{5}$ Manufacturing and

Development, NHS Blood and

Transplant, Bristol, UK

${ }^{6}$ Major Trauma Centre, Barts

Health NHS Trust, London, UK

${ }^{7}$ Blood Component Department, NHS Blood and Transplant,

London, UK

Correspondence to Josephine McCullagh; josephine.mccullagh@postgrad. manchester.ac.uk

\author{
Josephine McCullagh, ${ }^{1,2}$ Nathan Proudlove (D) , ${ }^{3}$ Harriet Tucker, ${ }^{4}$ Jane Davies, ${ }^{5}$ \\ Dave Edmondson, ${ }^{5}$ Julia Lancut, ${ }^{2}$ Angela Maddison, ${ }^{2}$ Anne Weaver, ${ }^{6}$ \\ Ross Davenport, ${ }^{4,6}$ Laura Green ${ }^{2,4,7}$
}

\section{ABSTRACT}

Recent research demonstrates that transfusing whole blood (WB=red blood cells ( $\mathrm{RBC}$ )+plasma+platelets) rather than just RBC (which is current National Health Service (NHS) practice) may improve outcomes for major trauma patients. As part of a programme to investigate provision of WB, NHS Blood and Transplant undertook a 2-year feasibility study to supply the Royal London Hospital (RLH) with (group 0 negative, ' 0 neg') leucodepleted red cell and plasma (LD-RCP) for transfusion of trauma patients with major haemorrhage in prehospital settings.

Incidents requiring such prehospital transfusion occur randomly, with very high variation. Availability is critical, but 0 neg LD-RCP is a scarce resource and has a limited shelf life (14 days) after which it must be disposed of. The consequences of wastage are the opportunity cost of loss of overall treatment capacity across the NHS and reputational damage.

The context was this feasibility study, set up to assess deliverability to RLH and subsequent wastage levels. Within this, we conducted a quality improvement project, which aimed to reduce the wastage of LD-RCP to no more than $8 \%$ (ie, 1 of the 12 units delivered per week). Over this 2-year period, we reduced wastage from a weekly average of $70 \%-27 \%$. This was achieved over four improvement cycles. The largest improvement came from moving near-expiry LD-RCP to the emergency department (ED) for use with their trauma patients, with subsequent improvements from embedding use in $\mathrm{ED}$ as routine practice, introducing a dedicated LD-RCP delivery schedule (which increased the units $\leq 2$ days old at delivery from $42 \%$ to $83 \%$ ) and aligning this delivery schedule to cover two cycles of peak demand (Fridays and Saturdays).

\section{PROBLEN}

There is evidence that transfusing whole blood (WB) for resuscitation of bleeding patients associated with trauma may be better than red blood cell (RBC) transfusion. However, manufacturing $\mathrm{WB}$ in the $\mathrm{UK}$ is technically difficult, the product has a shorter shelf life than RBC (14 vs 35 days) and the raw material (donated $\mathrm{O}$ negative $(\mathrm{O}$ neg) blood) is in short supply.

The Royal London Hospital (RLH) is part of Barts Health National Health Service
(NHS) Trust. The hospital is one of the four major trauma centres (MTCs) in London and hosts the base for London's Air Ambulance (LAA) service. LAA operates the Helicopter Emergency Medical Service (HEMS), which provides prehospital advanced-trauma care across the whole region covered by the London MTCs. Their helicopters and rapidresponse cars carry blood in Golden Hour boxes for transfusion. Over the last 4 years, they have administered a mean of 7.28 units of RBC per week (SD 2.60 units).

As part of the WB Feasibility Programme, in November 2018, NHS Blood and Transplant (NHSBT) started supplying RLH with (type $\mathrm{O}$ neg) leucodepleted red cell and plasma (LD-RCP) for use in the prehospital setting to treat major traumatic haemorrhage. In conjunction with this, RLH and HEMS made a clinical decision to change standard treatment from RBC to LD-RCP for the management of prehospital trauma patients who are bleeding.

By its nature, the availability of blood for prehospital transfusion is critical for patient outcomes, ${ }^{1}$ and the demand for it is highly variable (our baseline prehospital weekly demand data have a coefficient of variation of $57 \%$, which is higher than the benchmark for randomness represented by a Poisson distribution with the same mean).

There is a fine balance between supply and demand: ensuring that we have enough LD-RCP (or, potentially, eventually WB) for all prehospital trauma patients while minimising wastage. This product is manufactured from group $\mathrm{O}$ neg blood donations in particular short supply, and has a relatively short shelf life (14 days, after which it must be disposed of), and as part of the study, it was targeted at a limited group of patients. Wastage could therefore be high and result in significant loss to the NHS: financial and in treatment capacity. Minimising LD-RCP wastage would 
be crucial in deciding the feasibility of introducing a WB component nationally.

During set-up agreements for the feasibility study, supply of LD-RCP to RLH was agreed at 12 units per week. This being a new product, with short shelf life and targeted use, we had only been able to speculate about the potential level of wastage and what should be considered acceptable. The initial prestudy target wastage level was set (optimistically) at $8 \%$ on average. Higher wastage then could trigger reassessment of the WB Programme. The aim of the quality improvement (QI) work described in this paper was to achieve this low wastage rate by the end of the 24-month feasibility study. We used the Model for Improvement ${ }^{2}$ as a guiding framework. Later sections detail the metrics and change ideas. We used Plan-DoStudy-Act (PDSA) cycles of learning and improvement to test, adapt and implement our change ideas, with run and Statistical Process Control (SPC) charts to investigate system performance and demonstrate impacts.

Once the project started, we found that initial (baseline) wastage was very high $(70 \%)$ and that many units had limited shelf life remaining at delivery (only $42 \%$ were age $\leq 2$ days old and so having at least 12 days of opportunity for use). It became evident, therefore, that very considerable improvements were necessary.

\section{BACKGROUND}

There are four components of $\mathrm{WB}$ of importance in this paper: RBC, white blood cells (WBC or leucocytes), plasma and platelets, in the following combinations:

- RBC+plasma+platelets+WBC: WB, as donated blood.

- RBC (leucodepleted, LD): currently supplied to frontline NHS units for transfusion.

- RBC+plasma (LD): LD-RCP, as supplied in the feasibility study context here.

- RBC+plasma+platelets (LD): LD-WB, ideal WB component in development.

In the UK, all blood components are manufactured by NHSBT, who supply RBC, platelets and plasma for blood transfusion throughout the NHS.

Over the last decade, research has advanced our understanding of how the ratios of blood components transfused affect outcomes in trauma patients. Clinical trials have demonstrated that early and continuous resuscitation with RBC+fresh frozen plasma+platelets (in a 1:1:1 ratio, resembling $\mathrm{WB}$ ) reduces mortality. ${ }^{13}$ Therefore, in the UK, there is currently great interest in reintroducing a WB component for resuscitation of patients with traumatic major bleeding, particularly those presenting in prehospital settings.

To reduce the risk of variant CJD (Creutzfeldt-Jakob Disease) transmission, NHSBT removes WBC (leucocytes) from WB through LD filters. The LD filter currently used by NHSBT also removes platelets. So, in addition to the individual components (RBC, platelets and plasma), NHSBT can produce LD-RCP ( $\mathrm{RBC}+$ plasma in the same bag). NHSBT is currently assessing platelet-sparing LD filters to enable manufacture of safe WB (LD-WB). ${ }^{4}$

However, both LD-RCP and LD-WB have a much shorter shelf life than RBC: 14 days compared with 35 days. In the USA, unused WB is reprocessed after 10 days to produce RBC, ${ }^{5}$ avoiding blood component wastage. However, this is not possible in the UK due to regulatory constraints on hospital blood banks and hospital blood establishments, so in the NHS, there is risk of wastage.

Group O RhD Negative ('O neg') is considered the safest group to transfuse to patients with unknown blood groups. In addition to LD-RCP, O neg donations are also required for the manufacture of $\mathrm{O}$ neg $\mathrm{RBC}$ used for the transfusion of group $\mathrm{O}$ neg patients and for neonatal and for emergency transfusion of patients with acute bleeding requiring urgent resuscitation. In the UK, $12 \%$ of the demand for $\mathrm{RBC}$ is for $\mathrm{O}$ neg, but this group makes up only $8 \%$ of the population, ${ }^{6}$ so there is a shortage of donors and so of supply of this group ${ }^{6}$; donated $\mathrm{O}$ neg blood is a precious resource for the NHS.

\section{MEASUREMENT}

The global metric (or key performance indicator, KPI) was the wastage of LD-RCP (ie, the number of units that had to be disposed of at expiry of their shelf life) in units per week (and equivalently this as a percentage of the 12 units delivered per week). We realised an important internal (or process) metric was the age of LD-RCP units at delivery. We agreed a benchmark with NHSBT of 2 days old based on pre-existing logistical processes, so the metric was percentage with age $\leq 2$ days old at delivery.

Data were collected retrospectively from the laboratory information management system at RLH, WinPath. These data were analysed on a 1-week cycle and presented in the form of a dashboard including run and SPC charts. ${ }^{27}$

In the first phase of this QI programme, we established the current condition ${ }^{8}$ of this new process: mapping ${ }^{9}$ the LD-RCP flow (figure 1) and establishing baseline performance $^{2}$ on the metrics (figure 2 and table 1). In the SPC plot of the weekly blood wastage (the upper graph in figure 2), the first 14 datapoints are the preintervention period (14 weeks), which gives us the baseline performance: a mean wastage of 8.36 units per week ( $70 \%$ of the 12 delivered each week). Though the system is stable, this mean wastage was much higher than we had expected.

Later in the project, we also targeted the age of LD-RCP at delivery to RLH (shown in the lower graph in figure 2). This is dependent on the NHSBT supplier and was unaffected by our first set of interventions (PDSAs A1 and A2, which only changed the flow of blood downstream in the process (as shown in figure 1)). Therefore, we could use a longer period to establish the preintervention (pre PDSAs B1 and B2) performance, though since (as the performance is stable (as shown in figure 2)) using the 58 weeks to estimate this, rather than the 14-week baseline period used for wastage, makes little difference. We found 


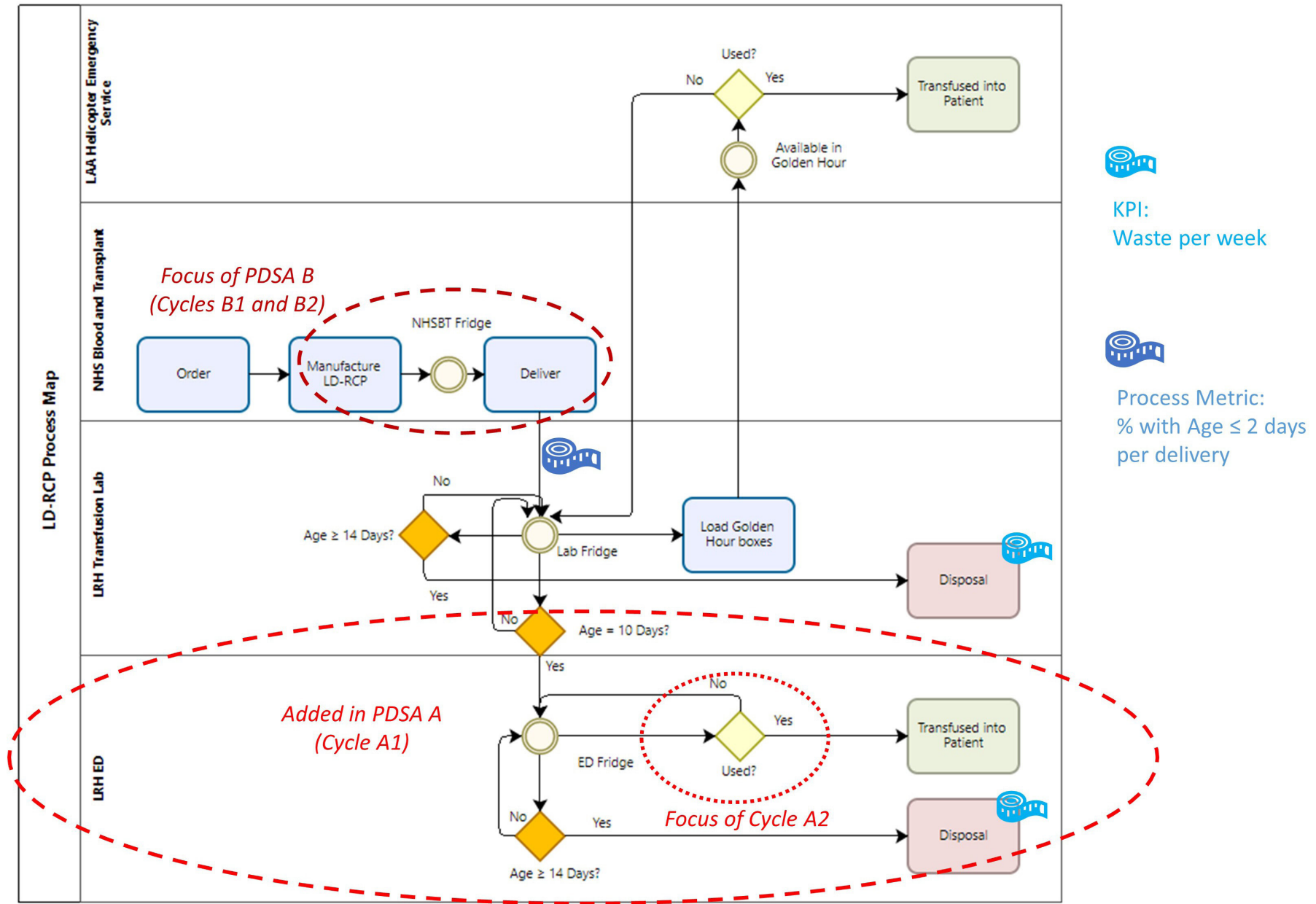

Figure 1 Process map. Royal London Hospital (RLH) ED, emergency department; KPI, key performance indicator; LAA, London's Air Ambulance; LD-RCP, leucodepleted red cell and plasma; NHS, National Health Service; NHSBT, NHS Blood and Transplant; PDSA, Plan-Do-Study-Act.

baseline performance on this metric to be a median of only $42 \%$ with age $\leq 2$ days (figure 2 lower graph).

\section{DESIGN}

Following analysis of the baseline data, we met to discuss the next steps. Though wastage was one of our main concerns prior to the start of the study, after reviewing the baseline data, it was clearly a bigger problem than we had expected.

The 'WB Programme Group' was established to evaluate new strategies to reduce the LD-RCP wastage, deal with other issues arising during the study and feed back results and progress to key stakeholders. This was a multidisciplinary team (MDT) consisting of the key feasibility study members (haematology consultants, emergency medicine and trauma consultants, transfusion scientists, a research fellow, blood component development scientists and blood component manufacturing specialists). As a group, we met every for 4 months to review the overall progress of the study and formulate new action plans. Key members directly involved in the management of LD-RCP delivery and stock management met more regularly to discuss compliance and review the data prior to the Group's main meetings.

The main idea was to widen access to the LD-RCP beyond the prehospital setting so that a unit approaching the end of its shelf life (and so becoming increasingly unlikely to be used for the targeted prehospital transfusion) could be used by other patients who could benefit. Although the LD-RCP component was developed mainly for use in the prehospital setting, as noted earlier (Background section), the rapid administration of this component (which is closer to WB than standard RBC) could produce improved outcomes for any major trauma patient. Therefore, a natural first target for any 'spare' LD-RCP was patients who present at the ED with trauma-induced major haemorrhage. For these patients, we expected ED staff to use any LD-RCP available in preference to RBC. If the wastage level was still above the $8 \%$ target, then a further strategy would be to transfuse LD-RCP at the end of its shelf life to other non-trauma patients who were bleeding and trauma patients in the operating theatre needing ongoing transfusion treatment with RBC and thawed plasma as part of routine care. 


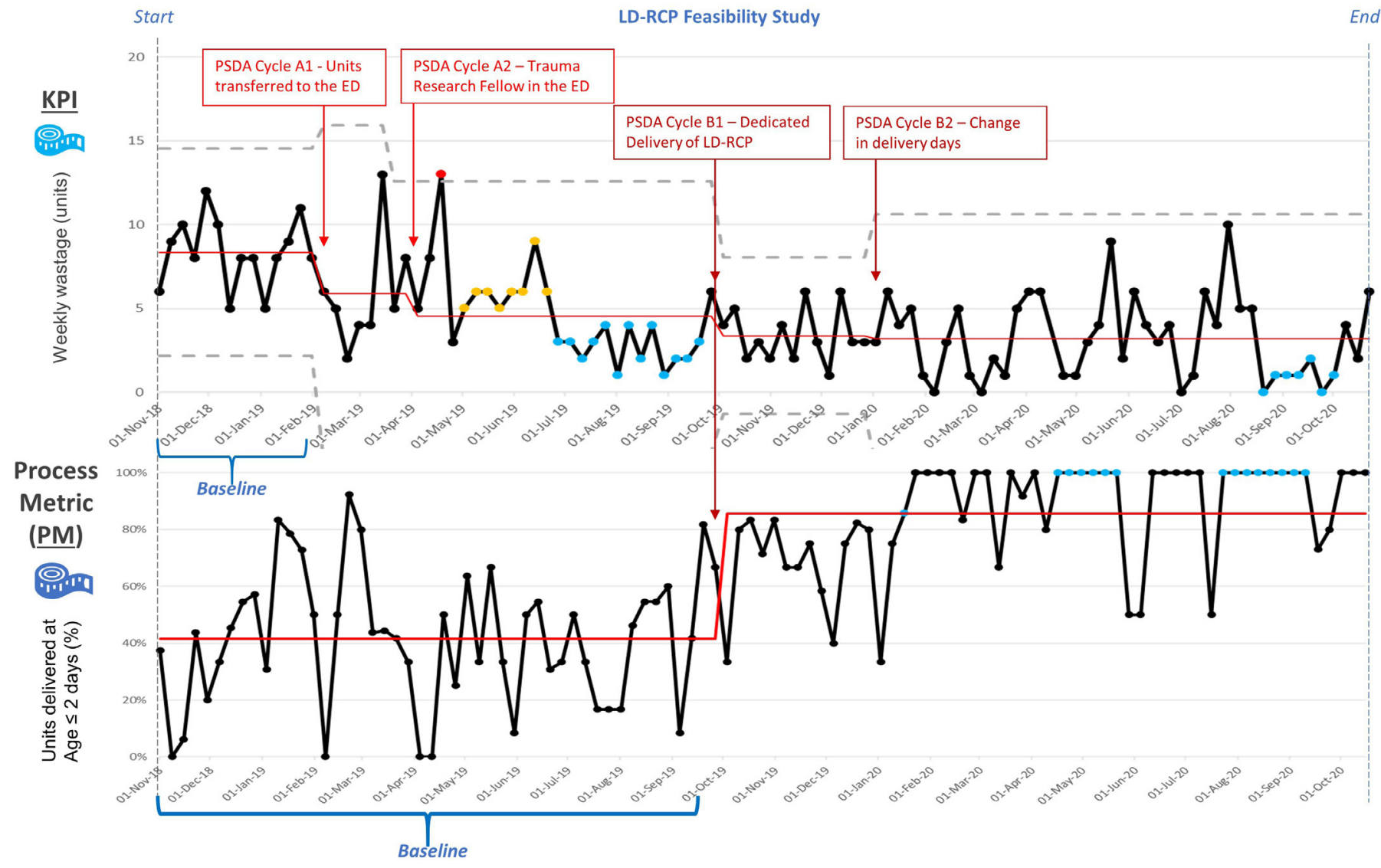

Figure 2 Performance metrics over the timeline of the project. ED, emergency department; LD-RCP, leucodepleted red cell and plasma; KPI, key performance indicator; PDSA, Plan-Do-Study-Act.

As the need for further improvement ideas became apparent, we also worked with NHSBT on delivery arrangements to increase the opportunity for use by increasing the proportion of units delivered at a 'young' age and coordinating the delivery day so the shelf-life window could span two peak-use periods (Fridays and Saturdays).

\section{STRATEGY}

We wanted to undertake three PDSA projects, but due to the COVID-19 pandemic, we were unable to implement the third PDSA (ie, transfusing LD-RCP to non-trauma patients with bleeding). In the end, we undertook two PDSA projects, each with two cycles. Each cycle was discussed in the WB Programme Group multidisciplinary meetings prior to commencement.

Table 1 summarises the progressive improvement cycles: aim, hypothesis, change idea, results and learning. The parts of the system changed or targeted are indicated on the process map in figure 1 , and the results are shown on the graphs of the two metrics in figure 2.

The first project ('Project A') was to extend the LD-RCP pathway by moving remaining units down to the ED fridge at 10 days old (only 4 days of shelf life remaining). (Note: this never emptied the transfusion lab and HEMS stock as by age 10 days a subsequent delivery would have occurred, and units were used oldest first.) We pursued this change idea first, as it was within our span of control in the hospital so could be started immediately; the subsequent project ('Project B') required discussion with NHSBT about their manufacturing and delivery cycles.

The first PDSA cycle (A1) implemented this change and tested the impact. It achieved the first (modest and interim) target, but there was a long way to go. The study phase picked up that ED staff were not always using LD-RCP when it was available. A second cycle (A2) was therefore initiated, with the trauma research fellows (TRFs) working with ED staff with the aim of making preferential use of LD-RCP, when available, into routine practice. This cycle involved MDT education, targeted messaging at handovers, weekly focus on blood transfusion and targeted teaching at new staff induction.

Following this focus on a new pathway to ED use, the Group agreed that another reconsideration of the whole process was required to attempt to further substantially reduce the wastage. Our baseline data highlighted that LD-RCP was not being delivered to RLH as fresh as desirable: one unit was already 9 days old, so only having 5 days of shelf life left (and so, under the new pathway, only 1 day for prehospital use before transfer to the ED). Project B therefore focused on LD-RCP delivery to RLH to increase and adjust its window of availability for use (particularly for prehospital use). The weekly LD-RCP delivery had been alongside other NHSBT products. We conducted 
Table 1 Improvement cycles

\begin{tabular}{|c|c|c|c|c|c|}
\hline PDSA cycle & Plan/prediction & Do & Study & Act & $\begin{array}{l}\text { Time } \\
\text { required }\end{array}$ \\
\hline Baseline & $\begin{array}{l}\text { Establish current condition } \\
\text { (map blood flow and analyse } \\
\text { baseline performance) }\end{array}$ & $\begin{array}{l}\text { 'Go and see' } \\
\text { analysis }\end{array}$ & $\begin{array}{l}\text { KPI: mean weekly } \\
\text { wastage }=8.36 \text { units } \\
(70 \%) \\
\text { PM: median } \% \text { age } \\
\leq 2 \text { days }=42 \% \text { per } \\
\text { week(oldest=9 days) }\end{array}$ & $\begin{array}{l}\text { Embark on cycles of } \\
\text { improvement, aiming } \\
\text { for mean weekly } \\
\text { wastage less than or } \\
\text { equal to one unit }(8 \%) \\
\text { by November } 2020\end{array}$ & 14 weeks \\
\hline $\mathrm{A} 2$ & $\begin{array}{l}\text { Encourage use by ED staff } \\
\text { Hypothesis: trauma research } \\
\text { fellows (TRFs) could } \\
\text { establish LD-RCP use as } \\
\text { routine practice for ED staff } \\
\text { Second target: KPI: mean } \\
\text { weekly wastage=four units } \\
(33 \%)\end{array}$ & $\begin{array}{l}\text { Existing TRFs work } \\
\text { in the ED to assist } \\
\text { with education, } \\
\text { training and } \\
\text { prompting use of } \\
\text { LD-RCP }\end{array}$ & $\begin{array}{l}\text { KPI: mean weekly } \\
\text { wastage }=4.54 \text { units } \\
(38 \%) \\
(\text { PM: median \% age } \\
\leq 2 \text { days }=\text { no change) }\end{array}$ & $\begin{array}{l}\text { SPC (figure 2) } \\
\text { suggests effective } \\
\text { after a time lag: four } \\
\text { units achieved most } \\
\text { weeks in second half } \\
\text { but capability low (little } \\
\text { safety margin). Further } \\
\text { improvement ideas } \\
\text { needed; tighten target } \\
\text { a little }\end{array}$ & 26 weeks \\
\hline B1 & $\begin{array}{l}\text { Dedicated LD-RCP delivery } \\
\text { slot } \\
\text { Hypothesis: more LD-RCP } \\
\text { received at age } \leq 2 \text { if had } \\
\text { dedicated delivery slots } \\
\text { Third target: KPI: mean } \\
\text { weekly wastage=three units } \\
(25 \%)\end{array}$ & $\begin{array}{l}\text { Work closely with } \\
\text { NHSBT (supplier) } \\
\text { using RLH metrics } \\
\text { and data, agree } \\
\text { dedicated delivery } \\
\text { slot rather than the } \\
\text { general delivery slots }\end{array}$ & $\begin{array}{l}\text { KPI: mean weekly } \\
\text { wastage }=3.38 \text { units } \\
(28 \%) \\
\text { PM: median } \% \text { age } \\
\leq 2 \text { days }=83 \% \text { per week }\end{array}$ & $\begin{array}{l}\text { Big improvement in \% } \\
\text { age } \leq 2 \text { days (process } \\
\text { metric) but only small } \\
\text { improvement in mean } \\
\text { weekly wastage } \\
\text { Further improvement } \\
\text { ideas needed; tighten } \\
\text { target a little }\end{array}$ & 13 weeks \\
\hline B2 & $\begin{array}{l}\text { Change LD-RCP delivery } \\
\text { days } \\
\text { Hypothesis: since } \\
\text { prehospital trauma } \\
\text { incidence highest on Fridays } \\
\text { and Saturdays, delivery to } \\
\text { cover } 2 \text { weekends would } \\
\text { decrease wastage } \\
\text { Fourth target: } \mathrm{KPI} \text { : mean } \\
\text { weekly wastage=three units } \\
(25 \%)\end{array}$ & $\begin{array}{l}\text { Change dedicated } \\
\text { delivery days, } \\
\text { Tue: two units, Wed: } \\
\text { four units, Thu: two } \\
\text { units, Fri: two units, } \\
\text { Sat: two units }\end{array}$ & $\begin{array}{l}\text { KPI: mean weekly } \\
\text { wastage }=3.19 \text { units } \\
(27 \%)(5 \text { weeks with } \\
\text { zero wastage) } \\
\text { (PM: median \% age } \\
\leq 2 \text { days: no change } \\
\text { expected) }\end{array}$ & $\begin{array}{l}\text { Ultimate target still } \\
\text { not met, small further } \\
\text { improvement in mean } \\
\text { weekly wastage (large } \\
\text { improvement since } \\
\text { the start). Variation still } \\
\text { high } \\
\text { (\% age } \leq 2 \text { days } \\
\text { appears to continue to } \\
\text { improve) }\end{array}$ & 17 weeks \\
\hline C & $\begin{array}{l}\text { Further extend the LD-RCP } \\
\text { pathway to include non- } \\
\text { trauma patients with major } \\
\text { bleeding. } \\
\text { Hypothesis: will further } \\
\text { increase in demand for LD- } \\
\text { RCP. } \\
\text { Fifth target: } \mathrm{KPI} \text { : mean } \\
\text { weekly wastage=one unit } \\
(8 \%)\end{array}$ & $\begin{array}{l}\text { Units' age } \geq 10 \text { days } \\
\text { to be also used for } \\
\text { non-trauma bleeding } \\
\text { patients in hospital }\end{array}$ & $\begin{array}{l}\text { Could not be } \\
\text { implemented due to the } \\
\text { COVID-19 pandemic }\end{array}$ & & \\
\hline
\end{tabular}

ED, emergency department; KPI, key performance indicator; LD-RCP, leucodepleted red cell and plasma; NHSBT, NHS Blood and Transplant; PDSA, Plan-Do-Study-Act; PM, process metric; RLH, Royal London Hospital; SPC, Statistical Process Control. 
an improvement cycle (B1) to work with NHSBT to coordinate manufacture and delivery, instituting a dedicated LD-RCP delivery. On further analysis and reflection, we realised that more trauma cases occurred (and therefore more blood was administered) on Friday and Saturday than any other days of the week. We therefore ran a further cycle (B2) to adjust the LD-RCP delivery schedule to allow more units' 14-day shelf life to span two Fridays and Saturdays.

Following the relative success of extending the LD-RCP pathway to include ED, we planned a final project ('Project C') to further extend the use of LD-RCP to non-trauma patients with major bleeding. This plan was approved in February 2020 by NHSBT and agreed by the WB Programme Group for implementation in April 2020. However, due to the COVID-19 pandemic, we were unable to complete this cycle due to lack of resources and rapidly changing staffing priorities within the NHS.

\section{RESULTS}

Our two main metrics of interest were total component wastage (KPI) and age of units on delivery (a process metric (PM)), measured on a weekly and monthly basis. Baseline data from the beginning of the study prior to any interventions demonstrated a stable baseline for measuring weekly component wastage.

As summarised in table 1 and shown in figure 2, over the four PDSA cycles, we reduced mean weekly wastage, from 8.36 units $(70 \%)$ to 5.88 units per week $(49 \%)$ and then 4.54 (38\%); 3.38 (28\%); and, finally, 3.19 units $(27 \%)$.

A year after the study started, cycle B1 addressed the $\mathrm{PM}$ of percentage with age $\leq 2$ days old through changes to the transport and delivery arrangements with NHSBT. We improved this metric from the baseline of $42 \%-83 \%$. In the lower graph in figure 2, the number of datapoints above the new median suggests that performance is making further good progress towards an ultimate target of $100 \%$ of LD-RCP units being delivered at age $\leq 2$ days.

Figure 2 demonstrates that the improvement was sustained for the remainder of the trial period (10 months after the final change). The results from this trial (including our design changes to reduce wastage) are now being used to plan the next stage of novel component supply trials.

\section{Lessons and limitations}

The aim of this project was to reduce the wastage level of LD-RCP. The two areas of focus were Project A, widening access to the blood product (and thus increasing demand), and Project B, maximising the useful availability of the product by adjusting the delivery schedule. The total wastage of LD-RCP component was reduced over the length of the study. However, although there were 17 individual weeks throughout this study period (of the total 103 weeks) in which we did manage to achieve the target wastage level of less than or equal to one unit, we never reached our overall target level of a mean of no more than $8 \%$. However, we were unable to implement and test the impact of the last QI change idea (ie, transfusing LD-RCP to non-trauma patients in hospital who are bleeding).

One area not well investigated in advance was the actual demand for blood for major trauma in the prehospital setting. The agreement on a constant delivery level of 12 units per week was based on a quick analysis of HEMS Golden Hour box provision rather than a detailed analysis of historical demand (ie, past use of RBC). Such an analysis could have examined weekly demand levels and (importantly) its variation, together with any trend and longer-term cyclical patterns.

Similarly, prior analysis of within-week demand cycles might have prompted, in the setup, design of delivery cycles around this and then, in turn, fitting the manufacturing schedule to the delivery cycle. This was only addressed halfway (a year) through the study, with Project B. The widening demand work (Project A) had a big impact on wastage (as expected), so starting with this seems sensible. However, the length of time until delivery root causes were addressed is an example of the conflict between (i) very fast-cycle experimentation and improvement and (ii) disentangling the effects of a single change (or a single closely related bundle of changes) and being able to demonstrate its impacts (eg, with SPC).$^{28}$ This was compounded in this study by it being of a new product/ service, so there was felt be no already-existing (historical) baseline performance data and that new datapoints accrued only once a week. The next phase of trials, currently being planned, will pick up on this and seek to make more effective use of data to predict demand.

In PDSA cycle A1, we unexpectedly found that ED staff did not use the new blood product (LD-RCP) whenever they could. EDs have many staff, with relatively high turnover. Cycle A2 took the remedial step of having TRFs working with them to educate and encourage take-up, a challenging task in a pressured environment. Our initiative benefitted from their ongoing educational input. Other trusts hosting prehospital trauma services generally have staff in similar roles; alternatively, this task could be taken on by dedicated education or transfusion practitioners, which all trusts should have.

The SPC chart highlights that there was a delay in the impact seen following the start of this cycle (A2). This lag in wastage reduction could demonstrate the time lapse between training/education and the application of the knowledge gained and in particular could be an example of how hard it is to change habits and to establish new routines, even with frequent practice and interaction with 'coaches'. 10

Later, further analysis has established that not all LD-RCP wastage had occurred at the end of its shelf life: $14.1 \%$ of LD-RCP units were discarded due to failures in cold chain (these units were not kept at the appropriate temperature when stored). Furthermore, we also found that only $16.5 \%$ of transfers of units to the ED occurred at the intended 10 days old (and $36 \%$ were $>12$ days old) 
representing opportunities for further improvement within the local system.

More detailed data analysis during the project might have picked this up and suggested additional PM. Coldchain failures could have been another target for QI cycles, discovering root causes and reducing their incidence. Additional cycles of the 'Project A' work (transfer to the ED) might have targeted compliance with the 10-day action point, perhaps considering QI ideas like visual management cues, $5 \mathrm{~S}$ workplace organisation and poka yoke mistake proofing. ${ }^{11}$

In future consideration of blood component flows, it would be very useful to institute routine analysis of wastage, perhaps with the sort of weekly datapoint SPC we have in this study, to monitor patterns (in close to real time) and to detect signals of things like changes in demand or ED staff practice.

\section{CONCLUSION}

Not all the PDSA cycles proved to be as effective in reducing the LD-RCP wastage as we expected, and the (ambitious) overall target of wastage of less than one unit per week $(8 \%)$ was not achieved. Nevertheless, incremental reductions were demonstrated across the study period, reducing the weekly wastage from a mean of 8.36 units per week $(70 \%)$ to $3.19(27 \%)$ by the end of the study period.

The biggest impact on wastage was making the LD-RCP available to be used in the ED and thus increasing the demand through cascading what would likely have been surplus units to a secondary use. Potential prehospital demand for LD-RCP had been very roughly evaluated prior to the start of the study. More detailed analysis of historical transfusion demand in both prehospital and ED settings could have refined this (perhaps obviating the need for the B1 and B2 improvement cycles) and also stimulated explicit thinking about the trade-off between prehospital shortage of LD-RCP (requiring step-down to RBC) and prehospital surplus LD-RCP (allowing step-up from $\mathrm{RBC}$ in the ED and potential final wastage).

A recent review of modelling of perishable blood product inventory, in that case platelets, notes that many modelling methods have been attempted..$^{12}$ Our future work will concentrate on a deeper level of analysis and modelling for our situation. In particular:

- Analysis of demand:

- To evaluate whether the weekly prehospital trauma demand can be forecast to a useful extent and with what lead time, as can be applied to some other emergency-care demand. ${ }^{13} 14$

- To consider the use of surplus LD-RCP for other bleeding patients (outside of trauma).

- Analysis of supply:

- If weekly demand is forecastable to a useful extent, to investigate whether it is feasible to institute a robust system to adjust supply and delivery accordingly.
- Development of a supply and demand model:

- To analyse the trade-off between shortage and surplus of LD-RCP, considering both expected (longrun average) value and (one-off) risks. This type of problem, with uncertain demand and a perishable product, is one that has been investigated using operational research modelling, ${ }^{12}$ 15-17 an approach that could be useful here.

Acknowledgements JM concluded this work as part of the quality improvement unit of the Higher Specialist Scientist Training Programme, run by Alliance Manchester Business School of the University of Manchester and the Manchester Academy for Healthcare Scientist Education, on behalf of the National School of Healthcare Science, part of NHS Health Education England.

Contributors JM, HT, LG, AW, DE, JD, JL, AM and RD made substantial contributions to the design of the work. JM performed the collection, analysis and interpretation of data. JM and NP drafted the work with LG and HT. All authors reviewed the draft. JM is the guarantor of the manuscript.

Funding The authors have not declared a specific grant for this research from any funding agency in the public, commercial or not-for-profit sectors.

Competing interests None declared.

Patient and public involvement Patients and/or the public were not involved in the design, conduct, reporting or dissemination plans of this research.

Patient consent for publication Not required.

Ethics approval The study received approval from the NHS Health Research Authority for data collection (ref number 236783).

Provenance and peer review Not commissioned; externally peer reviewed.

Data availability statement All data relevant to the study are included in the article.

Open access This is an open access article distributed in accordance with the Creative Commons Attribution Non Commercial (CC BY-NC 4.0) license, which permits others to distribute, remix, adapt, build upon this work non-commercially, and license their derivative works on different terms, provided the original work is properly cited, appropriate credit is given, any changes made indicated, and the use is non-commercial. See: http://creativecommons.org/licenses/by-nc/4.0/.

ORCID iD

Nathan Proudlove http://orcid.org/0000-0002-1176-8088

\section{REFERENCES}

1 Sperry JL, Guyette FX, Brown JB, et al. Prehospital plasma during air medical transport in trauma patients at risk for hemorrhagic shock. $N$ Engl J Med 2018;379:315-26.

2 Provost LP, Murray SK. The health care data guide: learning for data improvement. San Francisco, CA: Jossey-Bass, 2011.

3 Holcomb JB, Tilley BC, Baraniuk S, et al. Transfusion of plasma, platelets, and red blood cells in a 1:1:1 vs a 1:1:2 ratio and mortality in patients with severe trauma: the PROPPR randomized clinical trial. JAMA 2015;313:471-82.

4 Huish S, Green L, Curnow E, et al. Effect of storage of plasma in the presence of red blood cells and platelets: re-evaluating the shelf life of whole blood. Transfusion 2019;59:3468-77.

5 Yazer MH, Jackson B, Sperry JL, et al. Initial safety and feasibility of cold-stored uncrossmatched whole blood transfusion in civilian trauma patients. J Trauma Acute Care Surg 2016;81:21-6.

6 Foukaneli D, Bassey S, Bend M. Survey of group O D negative red cell use. 2018: NHS blood and transplant, 2018. Available: https:// hospital.blood.co.uk/audits/national-comparative-audit/medicalaudits/2018-survey-of-group-o-d-negative-red-cell-use [Accessed 21 Sept 2020].

7 Mohammed MA. Using statistical process control to improve the quality of health care. Qual Saf Health Care 2004;13:243-5.

8 Rother M. Toyota katA: managing people for improvement, adaptiveness and superior results. New York: McGraw-Hill, 2010.

9 NHS Institute for Innovation and Improvement. Improvement leaders' guide: Process mapping, analysis and redesign. NHSI: Coventry, 2005. 
10 Rother M. Toyota katA practice guide. New York: McGraw-Hill, 2018.

11 Boaden R, Harvey G, Moxham C. Quality improvement: theory and practice in healthcare. Coventry: NHS Institute for Innovation and Improvement, 2008. www.england.nhs.uk/improvement-hub/ publication/quality-improvement-theory-practice-in-healthcare

12 Flint AW, McQuilten ZK, Irwin G, et al. Is platelet Expiring out of date? A systematic review. Transfus Med Rev 2020;34:42-50.

13 Proudlove N, Brown C. Winter planning. seasonal cycles. Health Serv J 2002;112:24-5.
14 Proudlove NC, Black S, Fletcher A. Or and the challenge to improve the NHS: modelling for insight and improvement in in-patient flows. $J$ Oper Res Soc 2007;58:145-58.

15 Dillon M, Oliveira F, Abbasi B. A two-stage stochastic programming model for inventory management in the blood supply chain. Int $J$ Prod Econ 2017;187:27-41.

16 Qin Y, Wang R, Vakharia AJ, et al. The newsvendor problem: review and directions for future research. Eur J Oper Res 2011;213:361-74.

17 Osorio AF, Brailsford SC, Smith HK. A structured review of quantitative models in the blood supply chain: a taxonomic framework for decision-making. Int J Prod Res 2015;53:7191-212. 